\title{
O PAPEL DA MÍDIA NA DIVULGAÇÃO DE INFORMAÇÃO SOBRE MUDANÇAS CLIMÁTICAS EM MOÇAMBIQUE
}

\author{
Manuel Pastor Francisco Conjo ${ }^{1}$ \\ David Benjamim Chichango ${ }^{2}$ \\ Octávio Manuel de Jesus ${ }^{3}$
}

RESUMO: Moçambique é um país localizado na costa oriental de África, numa região vulnerável a eventos extremos derivados das mudanças climáticas. As mudanças climáticas são uma realidade na vida da população moçambicana, colocando os moçambicanos numa situação de vulnerabilidade dos efeitos dos principais eventos extremos. Em Moçambique, as mudanças climáticas manifestam-se principalmente através de eventos climáticos como seca, inundações e ciclones tropicais, cujos impactos afectam os sectores como agricultura, segurança alimentar, recursos hídricos, florestais, assentamento humano, infraestruturas e zonas costeiras. Este artigo pretende discutir o papel da mídia na divulgação de informação sobre mudanças climáticas em Moçambique, consciencializando a mídia nacional na busca de melhor tratamento e divulgação, de forma contínua e permanente, de informação relativa às mudanças climáticas para que as comunidades possam encontrar melhores formas de lidar com os efeitos das mudanças climáticas e dai reduzir os impactos, sendo que para sua elaboração baseou-se na pesquisa bibliográfica e pesquisa documental através de análise de variada informação disponível abordando esta temática. Neste sentido, para melhor divulgação da informação sobre as mudanças climáticas e ocorrência de eventos extremos associados entende-se importante a incorporação da mídia neste processo, pois o papel da mídia na divulgação de informações da situação de tempo atmosférico, clima, mudanças climáticas nas várias escalas de abordagens mostra-se cada vez mais importante.

Palavras-chave: Mudanças Climáticas. Moçambique. Mídia. Divulgação.

ABSTRACT: Mozambique is a country located on the east coast of Africa, in a region vulnerable to extreme events arising from climate change. Climate change is a reality in the life of the Mozambican population, placing Mozambicans in a situation of vulnerability from the effects of major extreme events. In Mozambique, climate change manifests itself mainly through climatic events such as drought, floods and tropical cyclones, whose impacts affect sectors such as agriculture, food security,

\footnotetext{
Mestrado em Gestão Ambiental pela Universidade Pedagógica de Maputo - Moçambique. Doutorando em Ciência Florestal pela Universidade Federal de Viçosa - Minas Gerais - Brasil. Instituição: Universidade Pedagógica de Maputo/Universidade Federal de Viçosa. E-mail: pastorconjooo7@gmail.com.

2 Mestrando em Gestão Ambiental, Universidade Pedagógica de Maputo. E-mail: davidchitlhango@gmail.com.

3 Doutor em Ciências Pedagógicas, Moçambicano, funcionário do Ministério da Ciência, Tecnologia e Ensino Superior. E-mail: octaviomzoor@yahoo.es.
} 
water resources, forestry, human settlement, infrastructure and coastal zones. This article aims to discuss the role of the media in disseminating information on climate change in Mozambique, raising awareness in the national media in the search for better treatment and continuous and permanent dissemination of information on climate change so that communities can find better ways to deal with the effects of climate change and hence reduce the impacts, and for its elaboration it was based on bibliographical research and documental research through the analysis of various information available on this subject. In this sense, for better dissemination of information on climate change and the occurrence of associated extreme events, it is considered important to incorporate the media in this process, as the role of the media in the dissemination of information on the weather, climate, climate changes in the various scales of approaches is increasingly important.

Keywords: Climate Change. Mozambique. Media. Dissemination.

\section{INTRODUÇÃO}

Moçambique é um país localizado na costa oriental de África, numa região vulnerável a eventos extremos derivados das mudanças climáticas. As mudanças climáticas são uma realidade na vida da população moçambicana, colocando os moçambicanos numa situação de vulnerabilidade dos efeitos dos principais eventos extremos, nomeadamente, cheias, secas e ciclones com características diferenciadas nas três regiões do pais.

Concorrem ainda para este facto a localização geográfica de Moçambique junto a convergência inter-tropical e á jusante das bacias hidrográficas partilhadas. Estes factos, concorrem para o aumento da vulnerabilidade do país a eventos extremos tais como secas, cheias e ciclones tropicais, que tem afectado grande parte da população. Por conseguinte, cenários de mudanças climáticas irão igualmente exacerbar frequência e intensidade destes eventos (MICOA, 2005).

De acordo com INGC (2009:9), Moçambique é o terceiro país mais afectado pelos desastres naturais em África, depois das Maurícias e Benin, e é o segundo mais vulnerável a eventos extremos na África Austral, como secas, cheias e ciclones tropicais, podendo esperar mudanças nos padrões sazonais de precipitação (frequência, intensidade, abrangência, duração e período de ocorrência). O impacto das mudanças climáticas sobre a precipitação, evapotranspiração de referência e temperatura é de crítica importância, particularmente em países em desenvolvimento como caso de 
Moçambique onde a base de sustento da população está ligada a agricultura de sequeiro.

De acordo com NUNES, L. (2007), o papel da mídia na divulgação de informações da situação de tempo atmosférico, clima, mudanças climáticas nas várias escalas de abordagens e desastres naturais, sobretudo os episódios de inundações, alagamentos e escorregamentos de massa tem se mostrado cada vez mais importante. Para este autor, a mídia desempenha relevante função na formação de opinião pública sobre os mais diferentes temas, o que reforça seu papel central na sociedade; porém, nem sempre a informação é repassada de forma adequada. Tal facto é particularmente relevante no caso de informações de carácter climático, estratégicas para uma série de condutas que norteiam acções específicas no território e que apresentam potencial para prevenir acidentes e perdas econômicas e/ou de vidas humanas.

Ocorre que entre sua origem e seu receptor a informação, intermediada pela mídia, pode sofrer distorções, simplificações, inconsistências e erros, comprometendo seu uso. Em geral as notícias podem ser confusas, contraditórias, erradas, simplistas, alarmistas e sensacionalistas, podendo induzir a mal entendidos ou mesmo descrença e desinteresse pela temática. (PRIZIBISCZKI, C. 2019)

Com isso, a mídia tem falhado em sua importante função social, tanto como elemento-chave na tomada de medidas preventivas ou soluções mais eficientes para minimizar as consequências de futuros episódios, como em sua função educativa, no entanto, considerando que as condições atmosféricas são complexas e centrais no cotidiano, e que a mídia é o principal canal para obter informações acerca desses assuntos para a grande maioria da população, a qualidade e até a ênfase na construção da informação são elementos de enorme relevância.

PRIZIBISCZKI, C. (2019), explica que as mídias podem ser classificadas seguindo diferentes critérios como, por exemplo, de acordo com a frequência (diária, no caso de jornais; semanal, quinzenal ou mensal, no caso de revistas, ou ainda mais rápida, com conteúdos constantemente actualizados, no caso de sítios da internet), com a abrangência (local, regional, nacional) ou mesmo de acordo com a qualidade da informação, tendo em vista que alguns veículos de comunicação são claramente sensacionalistas. No entanto, mesmo no caso de fontes de informação mais sérias e 
comprometidas com a qualidade, não chega a ser incomum a publicação de notícias apelativas, cujos propósitos são muito mais chamar a atenção do que realmente informar, inclusive nos assuntos relativos às situações do tempo e do clima.

Abordando essa temática, CARVALHO (2007), citado por ZAMPARONI, (202I), assinala um paradoxo criado pela mídia, ao difundir informações contrastantes: a autora exemplifica esse facto a partir de um periódico britânico, cujas notícias alertam quanto aos riscos das mudanças climáticas e a necessidade de acção com base em pesquisas científicas, mas igualmente veicula propagandas pagas de corporações que contribuem para agravar esse problema. Nesses casos fica patente, também, que a imprensa abdica da função social de ser um elemento-chave na articulação de assuntos centrais na contemporaneidade e na formação da cidadania consciente.

Por sua vez, LIEDTIKE (2003) assevera que na lógica liberal a finalidade de lucro suplantaria as educativas e culturais funções dos meios de comunicação.

Considerando que as condições atmosféricas são complexas e centrais no cotidiano, e que a mídia é o principal canal para obter informações acerca desses assuntos para a grande maioria da população, a qualidade e até a ênfase na construção do discurso são elementos de enorme relevância de forma a trazer informação real em tempo real.

Além do papel óbvio da imprensa, que é ser informativo, o jornalismo tem potencial para desempenhar inúmeras funções vitais na sociedade contemporânea, com destaque para seu carácter educacional, sociocultural e político, formador de opinião e influência. As informações de carácter climático conjugam aspectos atraentes para os públicos ouvinte, leitor e telespectador como possibilidade de previsão de acontecimentos, projecções de cenários possíveis e planificação de acções em diferentes prazos, o que as tornam cada vez mais presentes nas diversas mídias, divulgadas à luz de enfoques distintos. Contudo, faz-se necessário avaliar como as informações são passadas ao público e como elas são incorporadas a novas práticas e pensares.

Assinala-se que se de um lado a informação sobre tempo e clima é cada vez mais presente, por outro a forma como ela tem sido divulgada não contribui, necessariamente, para um conhecimento mais preciso dos fenômenos atmosféricos, que estão entre os que mais directamente influenciam a vida das pessoas. Além disso, a disseminação de informações fidedignas cumpriria o papel de colaborar na 
construção da cidadania e informar os tomadores de decisão acerca da importância dessas questões para a construção de locais mais saudáveis e seguros, factos que ao menos parte da imprensa moçambicana não tem tido papel proactivo.

Questões científicas como informações sobre mudanças climáticas e outros assuntos de natureza ambiental têm também ganhado maior projecção nas diferentes mídias e em alguns momentos esses assuntos recebem ainda maior atenção, como no período das reuniões anuais sobre as mudanças do clima.

As projeçcões do INGC (2009:13) antecipam que as mudanças climáticas em Moçambique se manifestem principalmente nos padrões de temperatura (com aumento médio entre 3 a $5{ }^{\circ} \mathrm{C}$ no período entre 2080-210o, registo de mais dias quentes e menos dias frios, com aumento da temperatura máxima e mínima); Padrões de precipitação (com comportamento irregular das chuvas em termos de momento de início e término e fenómenos de precipitação intensa num curto espaço de tempo)

Por exemplo, as mudanças climáticas podem trazer consequências graves resultado da ocorrência de ciclones, alterações sobre o regime hidrológico das bacias hidrográficas, entre eles aumento de cheias, secas, erosão, alteração da qualidade das águas e diversidade dos ecossistemas e do ambiente e desta forma trazer outros impactos sobre a sociedade e economia locais. Este artigo pretende discutir o papel da midia na divulgação de informação sobre mudanças climáticas em Moçambique, sendo que para sua elaboração baseou-se na pesquisa bibliográfica e pesquisa documental através de análise de variada informação disponível abordando esta temática.

Deste modo, torna-se importante incorporar novas abordagens relativamente as formas como é difundida a informação sobre a ocorrência, em Mocambbieque, de eventos extremos resultado das mudanças climáticas, e aqui podemos encontrar resposta através da participação da mídia no processo da divulgação da informação sobre as mudanças climáticas em Moçambique através das diversas plataformas.

Esta pesquisa surge pelo facto de ter-se constatado que várias vezes a população moçambicana é encontrada de surpresa e sem informação para dar resposta aos impactos que os fenómenos derivados das mudanças climáticas tem causado, por exemplo os camponeses não possuem informação detalhada sobre mudança de ocorrência de chuvas para início da época chuvosa, o que faz com que não consigam 
desenvolver a actividade de forma acertada. Não só, constata-se que a mídia moçambicana não tem passado de forma contínua e permanente informação sobre ambiente e mudanças climáticas. Deste modo, a realização desta pesquisa torna-se importante para consciencializar a mídia nacional na busca de melhor tratamento e divulgação de forma contínua e permanente a informação relativa às mudanças climáticas como forma de trazer informação real em tempo real para que as comunidades possam encontrar melhores formas de lidar com os efeitos das mudanças climáticas e dai reduzir os impactos.

Os impactos das mudanças climáticas sobre a economia e sociedade, despertam nas comunidades científicas a necessidade de desenvolvimento de novos instrumentos técnicos-metodológicos e bases teóricas capazes de subsidiarem estudos destinados ao conhecimento cada vez mais apurados buscando modelos de adaptação e resiliência e para a divulgação de informação sobre as mudanças climáticas entende-se importante a participação da midia neste processo.

\section{CONTEXTUALIZAÇÃO SOBRE MUDANÇAS CLIMÁTICAS}

O Painel Intergovernamental sobre Mudanças Climáticas - IPCC (2007) define Mudança Climática como as mudanças de clima no tempo devido à variabilidade natural e/ou resultado das actividades humanas (acções antrópicas, dentre elas a emissão de gases relacionados ao efeito estufa). (ADAM, K. e COLLISHONN, W. 2013)

De acordo com NUNES, L. (2008:67) a reconstituição do passado ambiental, inclusive climático, é um exercício bastante complexo. Para este autor, as condições que levaram às modificações do clima do planeta ao longo de sua história são apenas parcialmente conhecidas, muitas vezes colocadas no nível de hipóteses prováveis, até porque algumas das mudanças podem ter ocorrido devido à conjugação de condicionantes de diferentes ordens, que contribuíram com magnitudes distintas para alterar o clima.

$\mathrm{Na}$ reconstituição do passado climático do planeta no nível geológico, bem anterior à história do Homem no planeta, são utilizados métodos indirectos para inferir a composição atmosférica pretérita, como análises químicas da composição do gelo 
formado em épocas remotas, que podem revelar se as alterações ocorreram de forma lenta ou abrupta. (NUNES, L. 2008:67)

As causas da elevação da temperatura terrestre e seus consequentes efeitos são temas em construção, havendo ainda bastante dissensos sobre a responsabilidade humana no acirramento do efeito estufa. A despeito das discordâncias, têm-se obtido cada vez mais indícios, através de variadas áreas da Ciência, de que há uma tendência secular de elevação da temperatura do planeta. Nesse sentido, a comunidade científica mundial vem realizando esforços no intuito de esclarecer as mudanças climáticas e criar um sentimento de urgência e conscientização a cerca deste tema. Assim, tem-se divulgado relatórios que nos ajudam a entender como poderão se dar essas mudanças e quais seus possíveis impactos, como os relatórios do Painel Intergovernamental de Mudanças Climáticas (IPCC) e do Stern's Review on the Economics of Climate Change.

Segundo o IPCC (2007), a terra vem passando por um aumento na sua temperatura média e, até o final do século XXI, a tendência é que esta temperatura continue a subir, podendo chegar a alterações de $\mathrm{I}, \mathrm{I}^{\circ} \mathrm{C}$ até $6,4^{\circ} \mathrm{C}$, considerando a média de 1990 como referência. Além disso, são previstos aumentos na precipitação em algumas regiões e reduções em outras, bem como elevação dos níveis dos oceanos, frequência de furacões etc. (DIAS. 2014)

Do outro lado, MOLION (2007), critica o apelo público sobre o aquecimento global, destacando que a variabilidade natural do clima não permite afirmar que o aquecimento seja decorrente da intensificação do efeito estufa causada pelas actividades humanas ou mesmo que essa tendência de aquecimento persistirá nas próximas décadas, como sugerem as projeções produzidas pelo IPCC.

MOLION (2007) acrescenta que a aparente consistência entre os registros históricos e as previsões dos modelos não significa que o aquecimento esteja ocorrendo; na realidade, para ele, as características desses registros históricos conflituariam com a hipótese do efeito estufa intensificado: o planeta se aqueceu mais rapidamente entre 1925-1946, quando a quantidade de $\mathrm{CO}_{2}$ lançada na atmosfera era inferior a $10 \%$ da actual e se resfriou entre 1947-1976, quando ocorreu o desenvolvimento econômico acelerado após a Segunda Guerra Mundial. 
NETO (2008) explica que o IPCC defende que seus relatórios são imparciais, quando na verdade constituem análises prescritivas: eles encaminham os formuladores de política em direcção a determinadas opções e linhas de conduta que não são e nem poderiam ser neutras. Ele afirma que é impossível realizar escolhas desvinculadas de valores. Desse modo, para o autor, por mais que o IPCC se esforce, as possibilidades exibidas em seus relatórios se baseiam em escolhas - utilizando critérios científicos, mas ainda assim são escolhas. E, como tal, reflectiriam, em alguma medida, os valores defendidos pelos agentes que fazem essas escolhas quando optam por uma teoria, quando incluem certo dado, quando suprimem algumas expressões ou quando decidem quais exemplos serão citados.

LOVELOCK, J. (2006), sustenta que as perspectivas são sombrias, alegando que embora consigamos reagir com sucesso, passaremos por tempos difíceis, como em qualquer guerra, que nos levarão ao limite, estando em risco a própria civilização. Ele indica haver uma pequena chance dos céticos estarem certos, ou de que sejamos "salvos" por um evento inesperado, como uma série de erupções vulcânicas fortes o bastante para bloquear a luz solar e, assim, esfriar a Terra. Todavia, para o autor, apenas perdedores apostariam suas vidas em chances tão remotas, porquanto quaisquer que sejam as incertezas sobre o clima futuro, não há dúvida de que tanto os gases de efeito estufa como as temperaturas estão aumentando. Além disso, cabe referir a preocupação com a degradação ambiental, especialmente a partir da formação do Clube de Roma em 1968, com cientistas, industriais e políticos, os quais se reuniram para analisar e discutir os limites do crescimento econômico levando em conta o uso crescente dos recursos naturais. O grupo foi o pioneiro na identificação dos principais problemas à sobrevivência da vida do planeta, tais como a industrialização acelerada, o rápido crescimento demográfico, a escassez de alimentos e o esgotamento dos recursos naturais.

\section{IMPACTOS DAS MUDANÇAS CLIMÁTICAS}

A realidade mostra que actualmente existem evidências de que eventos extremos, como secas, cheias, ondas de calor e de frio, ciclones e tempestades, têm afectado 
diferentes partes do nosso planeta e de Moçambique, trazendo graves impactos e produzindo enormes perdas econômicas e de vidas.

Para BLANK, (2015), alguns sectores, por sua alta dependência às variáveis climáticas, sofrerão grandes perdas frente a estas drásticas mudanças, como é o caso dos sectores agrícola e da zona costeira. Estes impactos afectam o crescimento econômico e, portanto, o bem-estar da população.

De acordo com o BANCO MUNDIAL (2007), a mudança climática pressionará de maneira singular os pobres das áreas urbanas, os moradores dos assentamentos informais e outros grupos vulneráveis, como mulheres, crianças, idosos e portadores de deficiência e minorias populacionais. A mudança climática terá impactos sobre uma ampla variedade de sectores, como uso da terra, habitação, transportes, saúde pública, abastecimento de água e saneamento, manejo de resíduos sólidos, segurança alimentar e energia.

Os impactos das mudanças climáticas vão desde o aumento do número de fenômenos climáticos extremos e inundações até temperaturas mais altas e problemas de saúde pública. As cidades em zonas costeiras de baixa elevação, por exemplo, enfrentam uma dupla ameaça: a elevação do nível do mar e o aumento das tempestades. Os impactos específicos em cada cidade dependerão das mudanças climáticas efectivamente sentidas em cada uma delas (por exemplo, elevação das temperaturas ou aumento da pluviosidade), as quais serão diferentes de um lugar para outro. (BANCO MUNDIAL, 2007)

As mudanças climáticas em Moçambique manifestam-se principalmente através de eventos climáticos extremos tais como seca, inundações e ciclones tropicais associados a mudanças de temperatura e padrões de precipitação. $O$ impacto dos eventos extremos, prevê-se que piore no futuro (INGC, 2009). Isto afectará os sectores mais vulneráveis que incluem agricultura, segurança alimentar, recursos hídricos, florestais, assentamento humano, infraestruturas e zonas costeiras (MICOA, 2012).

Como reconhecimento de que as mudanças climáticas afectam negativamente os esforços de desenvolvimento do país, o governo comprometeu-se a incluir a adaptação na sua agenda nacional e implementar acções para o desenvolvimento harmonioso (MICOA, 2012). 
Por exemplo, em Moçambique, a experiência mostra que a seca tem impacto negativo em diferentes áreas de actividade, podendo causar diferentes efeitos tais como perda de culturas; secagem de pontos de água (poços, lagoas, lagos, riachos, rios etc.); redução da produtividade primária nas zonas costeira, afectando negativamente a pesca; redução de áreas de pastagem; subida de preços dos produtos agrícolas e de primeira necessidade; subida de importações de alimentos; aumento de apelos para ajuda externa; perda de vidas humanas e de animais; eclosão de doenças e perda de Biodiversidade. (MICOA, 2007)

Os impactos negativos das cheias são conhecidos tanto a nível mundial como em Moçambique, trazendo consequências como inundações; perdas de vidas e propriedades; perda de culturas; eclosão de doenças; deslocados; perda de Biodiversidade e ruptura das actividades normais em diferentes áreas.

O Governo de Moçambique reconhece que o país é vulnerável a catástrofes naturais e que as calamidades resultantes das mudanças climáticas são um dos factores que agravam a situação da pobreza absoluta em Moçambique, daí que o Governo preconiza como objectivos prioritários, no âmbito das mudanças climáticas, reduzir o número de vítimas humanas e de perda de propriedades, consolidar a cultura de prevenção e dotar o país de meios de prevenção e mitigação, e para o alcance desses objectivos é importante o envolvimento da mídia na divulgação de informação sobre as mudanças climáticas.

Segundo BLANK, (2015), ao falarmos dos impactos das mudanças climáticas, uma das questões de relevante projecção é a do aumento de pessoas deslocadas por causas ambientais, que se elevará significativamente até a metade deste século, produzindo uma quantidade enorme de indivíduos que, repentinamente ou em face de um processo gradual de destruição do meio ambiente, serão forçados a abandonar seus lares em busca de outro lugar onde lhes seja garantida a sobrevivência. Estima-se, inclusive, que o número de pessoas deslocadas por questões ambientais já supere a própria quantidade de refugiados perseguidos por razões políticas, sociais ou religiosas.

WOOD (200I), citado por (BLANK, 2015) que utiliza a expressão "migração ambiental”, explica que os factores ambientais, muito embora sejam, em muitas situações, ignorados ou subestimados, originam profundos impactos sobre as 
economias regionais e nacionais, influenciando, mesmo que indirectamente, os fluxos de migração.

'Refugiados ecológicos', migrantes ou 'refugiados do ambiente', 'refugiados do clima', 'eco refugiados', 'pessoas deslocadas em razão de uma catástrofe natural', 'êxodo ecológico', entre outros, são termos que reflectem o exílio, a migração ou deslocamento em razão de algo que atente ao meio ambiente. (COURNIL 2006), citado por (BLANK 2015)

Ademais, a discussão sobre as migrações ambientais foi potencializada nos últimos anos em face da perspectiva das alterações no meio ambiente decorrentes das mudanças climáticas. Estudos publicados pelo IPCC (2007) revelaram possíveis cenários para um futuro próximo que irão afectar significativamente a vida de milhões de pessoas em todo o mundo, independentemente do local onde vivem, da classe social ou da contribuição que tenham dado ao aquecimento global.

Ciclos hidrológicos mais intensos provocarão eventos extremos como tempestades, enchentes e inundações. Além do que, resultarão também no prolongamento dos períodos de seca e estiagem. Com isso, as áreas consideradas agricultáveis poderão diminuir e a desertificação avançará mais rapidamente, expulsando milhões de pessoas de seus ambientes, principalmente nos países mais pobres, onde os recursos tecnológicos não estão tão presentes na agricultura, o que poderia minimizar as perdas.

Moçambique, sendo um país vulnerável a ocorrência de eventos extremos (cheias, ciclones, tempestades tropicais e seca), resultantes das mudanças climáticas tem observado deslocação de grande parte de sua população que várias vezes é obrigada a sair do seu local de residência habitual em busca de melhores condições. Por exemplo, após a passagem dos ciclones Keneth e Idai no Norte e Centro do país vários indivíduos foram obrigados a abandonar suas residências afectadas para se refugiar em lugares com condições melhores e seguras. Na região Sul do país, devido à seca que se tem registado, por exemplo, no norte da província de Gaza, temos observado indivíduos se deslocando de lugares em lugares a procura de água tornando-se refugiados ambientais. 


\section{MATERIAIS E MÉTODOS}

Para o alcance dos objectivos traçados aplicou-se à abordagem qualitativa, que de acordo com OLIVEIRA (2011: 25), citado por CHICHANGO, (2018), é entendida como uma "expressão genérica". Isso significa, por um lado, que ela compreende actividades ou investigação que podem ser denominadas específicas, tendo sido aplicadas as pesquisas documental e bibliográfica por meio de consulta a diversos documentos e obras que abordam os assuntos tratados, tendo sido feita análise e selecção do essencial para a produção deste trabalho.

\section{APRESENTAÇẪO DOS RESULTADOS}

\section{RESULTADO I. A MÍDIA E DIFUSÃO DA INFORMAÇÃO}

De acordo com GOUVEIA, (2004). "A Sociedade da informação está baseada nas tecnologias de informação e comunicação que envolvem a aquisição, o armazenamento, o processamento e a distribuição da informação por meios electrónicos, como a rádio, a televisão, telefone e computadores, entre outros.

Estas tecnologias não transformam a sociedade por si só, mas são utilizadas pelas pessoas em seus contextos sociais, económicos e políticos, criando uma nova comunidade local e global: a Sociedade da Informação" (GOUVEIA, 2004).

Assim, GOUVEIA, (2004), sustenta que a sociedade da informação diz respeito à forma como a informação é difundida e divulgada a toda a sociedade através das tecnologias de informação e comunicação e que, sem o desenvolvimento tecnológico que tem decorrido ao longo deste tempo todo, provavelmente, nunca iríamos obter a informação assim tão rapidamente, como conseguimos alcançar agora.

A expressão mass mídia refere-se ao conjunto de técnicas utilizadas para a difusão de mensagens, que podem ser culturais, informativas ou publicitárias e são destinadas ao grande público, como exemplo temos a televisão, a rádio, a imprensa, o cinema; são os “ditos” meios de comunicação social familiares já há muito estabelecidos. Televisão, Rádio, Cinema, Imprensa...são formas de transmitir informação e fornecem entretenimento a todo o mundo (SORLIN, I997: I), citado por (NUNES, 2007) 


\section{RESULTADO 2. IMPORTÂNCIA DOS MEIOS DE COMUNICAÇÃO}

Segundo ESTEVES, (2003:169), citado por NUNES, (2007), “A importância dos meios de comunicação nos nossos dias é um facto absolutamente iniludível e o reconhecimento dessa importância apresenta-se tanto mais facilitado quanto as sociedade humanas atingem níveis mais elevados de desenvolvimento". Para este autor, na nossa sociedade a mídia assume uma certa importância já que suporta conteúdos que contribuem para os processos de produção e construção, de reprodução e reconstrução e de representação social da realidade e da cultura, contribuindo, também, na determinação da história das civilizações, das sociedades e das culturas.

De acordo com POMPEO e MARTINI (2012), o papel desempenhado pela mídia, em suas mais diversas esferas de actuação, é, em tempos de globalização, elemento fundamental para a compreensão da sociedade.

Segundo BIMBATO, (2016), dada a importância da comunicação para construção e reconstrução da sociedade, exigir informação de qualidade sobre o meio ambiente, com pluralidade de vozes e que busque interesses colectivos, é um direito de todo cidadão, ao tempo em que prestar informações com essa pluralidade, é um dever das organizações.

\section{RESULTADO 3. JORNALISMO AMBIENTAL E O PAPEL DA MÍDIA NA DIVULGAÇÃO DE INFORMAÇÃO SOBRE MUDANÇAS CLIMÁTICAS}

A formação holística na área do jornalismo, é compreendida de maior importância ao incorporar o jornalismo ambiental tanto para a formação dos profissionais de comunicação quanto para a manutenção do espaço público de debate que esse tipo de jornalismo oferece à sociedade num mundo envolvido em vários problemas de índole ambiental que precisam de ser expandidos ao público.

De acordo com BUENO (2007: 35), o Jornalismo Ambiental é o processo de captação, produção, edição e circulação de informações comprometidas com a temática ambiental e que se destinam a um público leigo, não especializado. $O$ jornalismo ambiental busca fazer a ponte entre especialistas do meio ambiente, como cientistas, técnicos e analistas ambientais, com a população geral. 
BUENO (2007) prioriza três funções do jornalismo ambiental: a função informativa, pedagógica e política:

A função informativa preenche a necessidade que os cidadãos têm de estar em dia com os principais temas que abrangem a questão ambiental. considerando o impacto que determinadas posturas (hábitos de consumo, por exemplo), processos (efeito estufa, poluição do ar e água, contaminação por agrotóxicos, destruição da biodiversidade, etc.) e modelos (como o que privilegia o desenvolvimento a qualquer custo) tem sobre o meio ambiente e, por extensão, sobre a sua qualidade de vida.

A função pedagógica diz respeito à explicitação das causas e soluções para os problemas ambientais e à indicação de caminhos (que incluem necessariamente a participação dos cidadãos) para a superação dos problemas ambientais.

A função política (aqui entendida em seu sentido mais amplo e não obviamente restrita à sua instância meramente político-partidária) tem a ver com a mobilização dos cidadãos para fazer frente aos interesses que condicionam o agravamento da questão ambiental. (BUENO, 2007)

"Grande parte das notícias sobre a questão ambiental tem como fonte a comunidade 1648 científica" (BARROS e SOUSA, 2008: 8). Um exemplo disso é a importância que é dada à publicação dos relatórios do Painel Intergovernamental sobre Mudanças Climáticas (IPCC) e das Conferências da ONU sobre o Meio Ambiente e o Desenvolvimento. A ponte entre cientistas e a população, entretanto, não é de troca de informações, mas sim, uma imposição de cima para baixo, onde a comunidade científica tem preferência e voz na mídia quando se trata de meio ambiente.

Para TRIGUEIRO (2005: 78), citado por BIMBATO, (2016), "o desafio é traduzir, sem prejuízo da informação, as descobertas que emergem dos meios acadêmicos e científicos", quando aborda o jornalismo ambiental e suas funções.

Cabe à mídia oferecer espaço de debate para que o tema meio ambiente, mudanças climáticas e sustentabilidade seja publicado levando as pessoas a pensarem mais criticamente sobre o futuro sustentável, pois a mídia tem um potencial capaz de fazer com que a população se envolva em um estilo de vida resiliente face às mudanças climáticas. 
Para BECK, (20II), o conhecimento científico, os avanços tecnológicos e a questão ambiental tal como aparecem na mídia ajudam a constituir o modo como entendemos diversos problemas contemporâneos, que caracterizam a alta modernidade, ou modernidade reflexiva como as mudanças climáticas.

HANNIGAN, (2006), citado por RODAS e DI GUILIO (2017), defende que na construção de um problema ambiental, como as mudanças climáticas, diversos factores estão presentes: (I) ter autoridade científica e validade para as reivindicações postuladas; (2) contar com divulgadores científicos, que transformam um objecto de estudo considerado fascinante e enigmático em uma reivindicação proactiva ambientalmente; (3) receber atenção da mídia, que mostra esse objecto como algo real e importante; (4) ganhar dramaticidade em termos simbólicos e visuais; (5) haver incentivos econômicos visíveis para a tomada de decisão sobre aquele objecto (neste caso, o problema ambiental); (6) garantir que haja um patrocinador institucional que garanta legitimidade à questão e sua continuidade na agenda

Nesse conjunto de factores, BECK (20II), considera que a mídia ganha destaque, já que, ao lado da ciência, das leis e da política, ela define, selecciona e dá visibilidade e legitimidade a um problema ambiental - ou o determinado risco.

Particularmente sobre as mudanças climáticas, a mídia desempenha papel-chave na construção das percepções e agendas públicas sobre o fenômeno. (ANDERSON, 2009)

ANDERSON (2009), explica que de modo geral, a questão climática ganhou maior espaço na mídia a partir de 1997, com a elaboração do Protocolo de Quioto, tratado internacional lançado naquele ano que propôs aos países desenvolvidos signatários um calendário para a diminuição da emissão de GEE. Os embates em torno do conteúdo e da ratificação do Protocolo de Quioto entre os diversos países adensaram as discussões políticas e acadêmicas sobre as mudanças climáticas.

A divulgação dos relatórios do IPCC, a realização de eventos internacionais relevantes na conformação de uma governança internacional das mudanças climáticas, a actuação de celebridades como porta-vozes das questões do clima e as recentes produções audiovisuais sobre o fenômeno também têm sido apontadas por alguns estudiosos como eventos detonadores ou com forte peso para a cobertura midiática sobre o fenômeno. 
Estudos mostram que as notícias ambientais tendem a perder espaço e atenção pública para outras questões consideradas mais interessantes ou pressionadoras. Essa abordagem, ainda que explicativa, é vista como linear e inflexível, especialmente ao olhar as interfaces entre mídia e mudanças climáticas. A compreensão de como as rotinas dos jornalistas, suas ideologias e relações com as fontes impactam a cobertura, as formas como a organização da qual o veículo de comunicação faz parte delineia o enfoque das notícias, bem como determinados significados e discursos têm sido reflectidos e reforçados na cobertura midiática. (ANDERSON, 2009).

HANNIGAN (2006), citado por RODAS e DI GUILIO (2017), argumenta que, para ganhar proeminência, um problema ambiental deve ser moldado em consonância com conceitos culturais existentes, deve ser articulado com as agendas política e científica, ter relação com o presente (e menos com o futuro) e ter uma agenda de acção atrelada ao nível internacional ou ao nível de uma comunidade local. ANDERSON (1997) observa ainda que, entre os factores que moldam as notícias jornalísticas, estão a frequência, a amplitude do nível de amplificação de um evento, a relevância em termos de proximidade cultural e a relação com a vida diária, a consonância com ideias preconcebidas sobre um grupo social ou uma nação, a raridade, a continuidade e o poder competitivo.

$\mathrm{Na}$ lógica da comunicação de massa, na visão de STURLONI (2006), citado por RODAS e DI GUILIO (2017), a relevância de um risco ambiental - por exemplo, as mudanças climáticas - depende também dos factores legais de noticiabilidade do evento: pluralidade de elementos de natureza sociocultural (proximidade, violação de normas de conduta), narrativa (presença de vítima identificada, atribuição de culpa, existência de um conflito) e técnica (disponibilidade de imaginação, inserção em um contexto preexistente). Ainda que a cobertura midiática sobre as mudanças climáticas já contabilize pelo menos quase três décadas, considerando os estudos que têm sido.

Deste modo, os meios de comunicação social desempenham um papel fundamental na representação social da realidade climática em Moçambique, podendo alterar os processos tradicionais de produção, de conhecimento e da circulação da informação, promovendo novas formas de socialização e, até, uma nova cultura. Dada a sua capacidade de alcançar um grande número de indivíduos em pouco tempo, a mídia 
pode ser capitalizada pelos decisores políticos de modo que possa ser aplicada na divulgação de informação sobre as mudanças climáticas reduzindo deste modo os impactos derivados das mudanças climáticas em Moçambique.

\section{CONCLUSÃO}

Através dos diferentes materiais analisados ao longo da realização desta pesquisa conclui-se que a mídia desempenha um papel bastante importante na formação de opinião pública sobre os mais diferentes temas. Tal facto é particularmente relevante no caso de informações de carácter climático, partilhando com o público e dotando-o de estratégias para uma série de condutas que norteiam acções específicas no território e que apresentam potencial para prevenir acidentes e perdas econômicas e de vidas humanas. Olhando para a vulnerabilidade de Moçambique aos eventos extremos torna-se importante que a midia nacional divulgue de forma permanente e contínua conteúdos relacionados ao ambiente e mudanças climáticas como forma de garantir existência de informação real em tempo real e desta forma reduzir os impactos derivados das mudanças climáticas, num país que está numa grande batalha de combate a pobreza. Particularmente sobre as mudanças climáticas, a mídia desempenha papel-chave na construção das percepções e agendas públicas sobre o fenômeno e dada a sua capacidade de alcançar um grande número de indivíduos em pouco tempo, a mídia podem ser capitalizada pelos decisores políticos de modo que possa ser aplicada na divulgação de informação sobre as mudanças climáticas reduzindo deste modo os impactos derivados das mudanças climáticas em Moçambique. Cabe à mídia oferecer espaço de debate para que o tema meio ambiente, mudanças climáticas e sustentabilidade seja publicado levando as pessoas a pensarem mais criticamente sobre o futuro sustentável, pois a mídia tem um potencial capaz de fazer com que a população se envolva em um estilo de vida resiliente face às mudanças climáticas. 


\section{REFERÊNCIAS BIBLIOGRÁFICAS}

ADAM, Katiucia e COLISHONN, Walter. Análise dos impactos de mudanças climáticas nos regimes de precipitação e vazão na bacia hidrografia do rio Ibicuí. Revista brasileira de recursos hídricos. Volume i8n3. 2013.

ANDERSON, A. Media, Politics and Climate Change: Towards a New Research Agenda. London. Sociology Compass. 2009.

ANDERSON, A. Media, culture and environment. London. UCL Press Limited. 1997. BANCO MUNDIAL. Guia de adaptação a mudança climática nas cidades. Washington DC. 2007.

BARROS, Antônio e SOUSA, Jorge. A Escola de Chicago e os estudos de jornalismo ambiental no Brasil e em Portugal. Natal-RN. Editora Intercom. 2008.

BECK, U. Sociedade de risco rumo a uma outra modernidade. Tradução de Sebastião Nascimento. 2. Ed. São Paulo. Editora 34. 20II.

BLANK, Dionis. O contexto das mudanças climáticas e as suas vítimas. Ceará. Universidade Federal do Ceará.

BUENO, Wilson. Jornalismo Ambiental: explorando além dos conceitos. Editora UFPR. 2007.

CHICHANGO, David. Geodiversidade do Baixo Umbelúzi. Usos e impactos sócio ambientais de 2005 a 2018: Caso do Bairro 7 de Setembro em Boane. (Monografia Cientifica). Maputo. Universidade Pedagógica de Maputo. 2018.

DIAS, José. Mudanças climáticas e impactos económicos. Santa Maria. Universidade Federal de Santa Maria. 2014.

GOUVEIA, Luís Manuel Borges "Sociedade da informação: Notas de contribuição para uma definição operacional”. 2004.

INGC (Instituto Nacional de Gestão de Calamidades). Estudo sobre o impacto das alterações climáticas no risco de calamidades em Moçambique. Maputo. 2009.

IPCC. Câmara dos Deputados/Consultoria Legislativa, Brasília.2013.

(IPCC) 2014: Sumário para os tomadores de decisão do Quinto relatório de avaliação (2014). Traduzido por Iniciativa Verde, São Paulo, 2015. 
LIEDTKE, P.F. - Políticas públicas de comunicação e o controle da mídia no Brasil. Tese - Revista Eletrônica dos Pós-Graduandos em Sociologia Política da UFSC. Santa Catarina. UFSC. 2003

LOVELOCK, James. A vingança de Gaia. Rio de Janeiro. Editora Intrínseca. 2006. MINISTÉRIO PARA COORDENAÇÃO DA ACCÃO AMBIENTAL (MICOA). Avaliação da vulnerabilidade as mudanças climáticas e estratégias de adaptação. Maputo. 2005.

MINISTÉRIO PARA A COORDENAÇÃO DA ACCÃO AMBIENTAL (MICOA). Estratégia Nacional de Adaptação e Mitigação de Mudanças Climáticas. Moçambique. 2012.

MOLION, Luiz Carlos. Desmistificando o aquecimento global. Intergeo Editora., v. 5. 2007 .

NETO, Petrónio de Tílio. Eco político das mudanças climáticas: O IPCC e o ecologismo dos pobres. Tese (Doutorado em Ciência Política). São Paulo. Universidade de São Paulo. 2008.

NUNES, Luci. O papel da mídia na difusão da informação climática: o El Niño de 1997-98. Rio Claro. Geografia. 2007.

NUNES, Luci. Mudanças climáticas: físicas e socioeconómicas. Camara dos deputados. Biblioteca digital. Brasil. 2008.

NUNES, L. e ZAMPARONI, C. A. A Mídia em Foco: Exemplos de Desinformação Climática in Multidimensão e Territórios de Risco. Coimbra. Imprensa da Universidade de Coimbra. 2014.

NUNES, Sónia. Sociedade de informação. Coimbra. Universidade de Coimbra. 2007. POMPÉO, Wagner e MARTINI Alexandre. O papel da mídia na construção da democracia, cidadania e justiça no mundo globalizado: um estudo voltado aos efeitos das ações de imprensa e micropolíticas fundadas no espaço local. Santa Maria Universidade Federal de Santa Maria. 2012.

PRIZIBISCZKI, C. A comunicação das mudanças no clima: finalmente um avanço. In ECO. 2019. 
RODAS, Caroline e DI GUILIO, Gabriela. Mídia e mudanças climáticas: Uma análise sobre tendências da cobertura jornalista, abordagens e critérios de noticiabilidade. São Paulo. UFPR. 2007.

ZANGALLI JR., P.C. Entre a ciência, a mídia e a sala de aula: contribuições da geografia para o discurso das mudanças climáticas. (Dissertação de Mestrado). São Paulo. UNESP.2013.

ZAMPARONI, Cleusa. O clima e a mídia. Cuiaba. Universidade Federal do Mato Grosso. 2021. 